Emergency care

\title{
Reforming emergency care; for patients
}

\section{Lammy}

\section{Working together for the benefit of patients}

$\mathrm{E}^{\mathrm{n}}$ mergency care is important to me for lots of reasons, but for one in particular: it's important to patients. We know that A\&E services-and by implication all the components that make up the whole emergency care system-are among patients' top concerns.

Within A\&E I believe a critical concern for patients is how long they have to wait for clinical care, and I can't blame them. When you are in pain, frightened, or with a sick child each hour you wait feels like purgatory. And when patients get stressed the staff can suffer too.

We have a target for waiting times in A\&E-by the end of 2004, no one (unless it's clinically advisable) should spend more than four hours between arrival and admission, transfer or discharge. I think that is reasonable and achievable, even modest in some ways, but I don't expect it to happen by magic. The way we organise and cooperate across the whole emergency care system has to change.

See and Treat wasn't the government's idea but, having taken clinical advice, we do think it's a good one. There is a growing body of evidence indicating that it can cut waiting times for patients with minor problems without adversely affecting times for others. The guidance on how to make See and Treat work was developed in conjunction with the BAEM and the RCN and endorsed by them, but it's not a strict blueprint that we expect to see implemented to the letter everywhere. It can only work properly if it's applied in a flexible and open minded way that reflects local conditions. What matters is that it makes a real difference to patients' experience of A\&E.

See and Treat works, but we know that it isn't the whole answer. Staff working in A\&E are very busy people, and it isn't always easy for them to stop and think about how they do their jobs. That's where the emergency services collaborative and local emergency care networks can help-by giving staff from across the whole system the time and space to get together, iron out problems, and spread good ideas and practice.

Next we will turn our attention to all the other factors that can keep patients waiting in A\&E, especially those patients who may need to be admitted. Things like bed management, diagnostics or admissions and discharge procedures can present more complex and awkward problems but that doesn't mean they are insoluble. The NHS Modernisation Agency is already doing good work that I hope can continue and develop through the emergency services collaborative and networks.

While a lot of this can be done without extra money, I don't want progress to be held back by a lack of resources. The NHS is receiving historically high increases in its funding, and have made specific allocations to Trusts and PCTs towards the cost of emergency care leads, emergency care networks, and more nurses in A\&E. PCTs must make their contribution to meeting one of the most important challenges now facing the NHS. That doesn't mean tossing money around like confetti in the hope that some of it does some good, but it does mean we need to be receptive to well thought out ideas that can deliver demonstrable benefits to patients.

I hope you'll forgive me for concentrating on what needs to be done rather than on what has been achieved already. It doesn't mean that I don't understand the progress that has been made or that I don't appreciate it. I do, and so do my colleagues in government, but it is a fact of life that there is always more to be done. If it delivers an emergency care system that staff and patients can really be proud of, it will have been worth it.

Emerg Med J 2003;20:1 12

\section{Author's affiliations}

D Lammy, Parliamentary Undersecretary of State for Health, House of Commons, London, UK

Correspondence to: David Lammy, MP

\section{Skillmix: an advance or an excuse?}

\section{K G M M Alberti}

O ver the past five years there have been many changes in the way that emergency medicine departments work. This has been given recent prominence and encouragement by the recognition of the governmentfinally-that emergency medicine was in difficulty. There is also the recognition that the A\&E department is the shop window of the NHS. A long trolley wait today is a newspaper headline tomorrow-particularly in London and the south east.

So why do we have a problem? Much is historical. Many A\&E departments changed little for several decades after the birth of the NHS. A large, unattractive waiting room was the norm with all sorts of patients mixed in together. There was tacit acceptance that one would wait-sometimes for several hours. A\&E had neither the glamour of surgery nor the academic backup of internal medicine. It was looked on as a necessary evil-a carbuncle on the side of the hospital. A\&E consultants and SHOs worked hard and well, as did the A\&E nursing staff, but opportunities to change practice were in short supply.

The past two decades have seen a gradually accelerating change in work, attitudes, and staffing. There has been an increasing number of consultant appointments with a new breed of energetic, committed individuals coming from a predominantly medical, rather than surgical, basic training background. Emergency medicine is now looked on as an attractive specialty without particular recruitment difficulties.

A breakthrough came recently with the publication of Reforming emergency care from the Department of Health-but with important input from Royal Colleges and Faculties. This pointed out that 
the long waiting commonly seen in A\&E departments, first to be seen at all and second to obtain a bed if admission was deemed necessary, was totally unacceptable. The government introduced a target of four hours as the maximum time that a patient should spend from arrival to the department to being discharged or admitted. This above all has focused attention on A\&E departments, although the point is increasingly made that emergency care is a whole system problem. It involves prehospital care and post-hospital capacity as well as the A\&E department itself.

So where does skillmix fit in? It follows automatically from two facts. Firstly, there are too few doctors to deliver all the care that is required. This has been brought into sharp relief by the imminent introduction of the European Working Time Directive, which will cut drastically into the working time of junior doctors, as well as the demand, more and more, for consultant delivered care on the grounds of quality, speed, and safety. Secondly, and perhaps more important, is the result of putting patient needs first. Doing this one can work out a series of skills and competencies needed to achieve a timely, high quality outcome. The next move is to establish who has or could have these skills and competencies. Using this approach it is immediately apparent that much can be done well and competently without 10 to 15 years of medical training (and some perhaps better!).
The impact of these two factorstogether with increasing skills of the nursing workforce-has been to cause radical rethinking by the A\&E community of who should do what. There is still some resistance from those preferring to hide in their professional silos, but this is counterbalanced by management, politicians, and professional thinkers who have accepted that the status quo is not an option-and that patients deserve better than lengthy waits to be seen or to be admitted. The past two to three years have seen a dramatic rise in the number of emergency nurse practitioners undertaking a variety of tasks, generally involving minor injuries/ illnesses, Walk in Centres, or triage. But more can be achieved. At present the position of the emergency nurse practitioner is hampered by the lack of clear definition of training needs and national criteria for training programmes. Emergency care practitioners are also being developed, so far on a pilot basis. Care facilitators are also appearing and having an important beneficial impact on patient flow, while physiotherapists are playing an increasing part with regard to the elderly population and orthopaedic problems. Many of the new developments in skillmix have come from emergency physicians and senior nurses working together in programmes such as IDEA, CWP, and the Emergency Collaboratives, all of which are accelerating change.
Obviously some control is needed to ensure that the quality of care matches the increase in quantity and speed of care. This is up to the emergency team as a whole. Equally someone has to lead and take responsibility for the work of the team. I would contend strongly that this should remain the domain of the consultant in emergency medicine, who has the breadth and depth of training to oversee all aspects of care.

The increased use of different people - that is, skillmix - is helping patient care. Even when we have sufficient consultants in post ( six or seven for a 24 hour acute hospital) in 10 to 12 years time, the contribution made by nonmedical clinicians will still be needed. Such clinicians have much to offer patients and complement doctors rather than replace them. Finally, we are moving to an emergency care system, which is both recognised as being of paramount importance to patient care and will be one of which we can be proud.

Emerg Med J 2003;20:112-113

\section{Author's affiliations}

K G M M Alberti, National Director for Emergency Access, Department of Health, Richmond House, 79 Whitehall, London SWIA 2NS, UK

Correspondence to: Professor Sir George Alberti; george.alberti@doh.gsi.gov.uk

\section{Reforming the UK emergency care system \\ M W Cooke}

\section{Improving the care not just the figures}

W e are all too well aware of the problems of waits in emergency health care. They are consistently the issues that the public and media comment about when asked about emergency medicine. Delays in the emergency care system are invariably attributable to a complex mixture of problems before, during, and after the hospital episode. ${ }^{1}$ Measures of performance in emergency care have focused on a few specific areas, for example, ambulance response to arriving at an incident and waiting times in the emergency department. $^{2}$ The blame for poor performance has often been cast on the area where the indicator has been measured rather than at the root cause. This has also allowed other areas to shy away from their responsibilities. These are all symptoms of an emergency care system that is fragmented, ${ }^{3}$ with each component struggling to solve its own problems.

Some issues can be partially solved by one organisation working alone but this is rare.

An ambulance service could achieve an eight minute response for all category A calls by its own action. But this would be an inefficient method of achieving such change-how much better to look at joint initiatives. Rather than blaming hospitals, working with them to reduce turnaround times and free up ambulance resources. Looking at how they can take some patients to more appropriate destinations, resulting in a better service for the patient, and a more even spread of the workload. Within the hospital, the most important factor in preventing waits in A\&E is the hospital bed occupancy. ${ }^{4}$ But many colleagues will recognise that bed management is all too often a fire fighting function by comparatively junior staff not a predictive planning function with responsibility lying with an executive director. But the factors affecting bed occupancy are also outside the hospital. The ability of the community to accept patients back from the acute hospital is a key determinant of hospital length of stay, including availability of social care but also of primary medical care. It is however easy to use the whole system concept to blame others. None of us work in perfect systems and we can all make changes in our own areas to contribute to improved care. Ours may not be the biggest cause of delays in the system but, we have more influence to change our own area. 
This edition of EMJ highlights many projects across the whole system of emergency care and confirms the enthusiasm for change.

Emergency care networks are now being established in the UK, bringing together all organisations involved in emergency care in one locality. Their aim should be to look at issues across the whole system. In the past, such groups looked at contingencies for when the system was overloaded. This needs to change to looking at how the system can be changed to improve care at all times. By undertaking patient tracking, networks can rapidly discover where the system faults lie. Personal observation has shown how often the faults lie in organisations working independently without appropriate mutual respect and trust. I believe there should be a lay person on each network group, perhaps chairing it, so that vested interests and perverse incentives are overruled in favour of quality of care.

But performance indicators can also deceive. A patient may get their ambulance in eight minutes and be through A\&E in less than four hours and still have a poor experience of emergency care. Often too much effort is focused on improving the figures not the care. At worst, this is demonstrated by the time invested in defining, interpreting, and manipulating the figures rather than investing it in patient care improvement. Examples that I have witnessed include hospitals not allowing ambulances to unload as they believe A\&E time starts when the patient is unloaded from the ambulance trolley, or declaring certain areas of $\mathrm{A} \& \mathrm{E}$ as a ward so the patient is considered to have been admitted. Fortunately clinical staff still act as the champions of quality care and highlight these problems, but we need to ensure their voices are heard and acted upon. More commonly the effort to improve a performance indicator has focused on establishing new systems simply to improve the performance indicators results, for example moving patients direct to coronary care unit when A\&E is delivering better door to needle times than the coronary care unit. The goal is not improved performance indicators, it is improved care. The best judge of care is the patient. Why do we not have patient representatives on our emergency care management groups? Why do we not use patients to monitor the performance indicators and the patient experience?
Emergency care is a complex component of health care. If I could change one thing to help emergency care, it would be to include a user and a junior member of nursing and medical staff on every committee that talks about emergency care. In my experience of visiting many emergency care communities, they know the problems and, very often, the solutions.

Emerg Med J 2003;20:1 13-114

\section{Author's affiliations}

M W Cooke, Senior Lecturer in Emergency Care, University of Warwick, UK

Competing interests: the author is also A\&E Advisor to the Department of Health.

Correspondence to: $\operatorname{Dr} M$ W Cooke; matthew.cooke@doh.gsi.gov.uk

\section{REFERENCES}

1 Audit Commission. Acute hospital portfolio: review of national findings-accident and emergency. London: Audit commission 2001. (http://www.audit-commission.gov.uk/ publications/aande.shtml)

2 Department of Health. NHS Plan. A plan for investment. A plan for reform. London: HMSO, 2000.

3 Department of Health. Reforming emergency care. London: Department of emergency care.
Health, 2001.

4 Bagust A, Place M, Posnett JW. Dynamics of bed use in accommodating emergency admissions: stochastic simulation model. BM 1999:319:155-15.

\section{The advances and evidence base for prehospital care}

\section{MacFarlane}

\section{Validation is needed to determine the true effectiveness of perhospital care}

$\mathrm{P}$ rehospital care is a developing and exciting area of emergency practice. It comprises a variety of emergency care domains, including ambulance and emergency medical services (EMS) practice, medical rescue, prehospital physician response and medical direction, retrieval medicine, (including aircraft and seaborne activities), dispatch and communications, telemedicine, disaster medicine. Increasingly, there is greater interaction between various emergency authorities, including fire service, police, civil defence, military authorities. Greater interaction with hospital emergency departments is also being encouraged.

The major problem has been auditing the effectiveness of prehospital care and whether it is cost effective, or even worth the effort at all! Strong emotions and forcible opinions exist among both supporters and detractors.

The fundamental problem has been the lack of evidence based assessment of prehospital practice. The paucity of prehospital care in Cochrane reviews is evidence of this. A fundamental part of the problem has been the lack of reliable indicators to measure effectiveness, commonly because of the large variety of variables operative in this area. Attempts have been made to develop indicators, mainly in North America, ${ }^{1-3}$ but there has not been general acceptance of appropriate indicators. In many EMS systems response times and on scene times are used as standards of system effectiveness. ${ }^{45}$

As a result of all this, there have been reports questioning the effectiveness of prehospital care. ${ }^{6-9}$ Other reports, supporting the value of prehospital care, especially Advanced Life Support, have emerged. ${ }^{10-12}$ Commonly prehospital care providers see their end point as the delivery of a live patient to a hospital. There is often little attention paid to the final outcome of the patient, and whether or how prehospital care influenced this. Much work needs to be done still on the development of accurate indicators for prehospital emergency care, and the development of these is, surely, fundamental to the evolution (and indeed, survival) of prehospital care systems. Attention to this is one of the most important activities in which prehospital care providers can engage.

Another problem is the tendency to consider prehospital care to be a homogeneous entity. It certainly is not! However, important papers by eminent personalities in large North American trauma centres of international repute are being regarded by many as "the law" as regards prehospital care. The edicts emanating from these excellent institutions may well be correct and appropriate in such well equipped centres, served by first class EMS, with short prehospital times. They may, equally, not be valid in rural practice, in small community hospitals, in developing countries, or in systems not modelled on North American 
practice. Care must be taken, therefore, in interpreting such edicts. Equivalent research work needs to be undertaken in some of these other areas.

Despite all the difficulties, however, advances have taken place in prehospital care. The realisation that, particularly in the case of trauma, the less the prehospital time, the better the outcome, has resulted in the shortening of on scene times, reduction in time consuming on scene procedures, and rapid transport, utilising in transit resuscitation. Fundamentals are being re-visited; for example, immediate and more effective on scene and in transit haemostasis, rather than attempted high volume fluid replacement. A potential better utilisation of advanced paramedics is the utilisation of their Advanced Life Support skills as part of a resuscitation team in lesser resourced peripheral hospital emergency departments, rather than at the roadside.

A more logical use of spinal immobilisation techniques is evolving, due to international studies. ${ }^{13}$ The "on again/off again" use of pneumatic anti-shock garments has now passed the stage of raw emotion, and the device is now being used much less, but more logically. A current controversy is the use of rapid sequence induction by non-physician personnel in the prehospital environment. This remains at the stage of high emotion, and the jury is still out on this. With regard to prehospital thrombolysis for myocardial infarction, this has been reasonably well accepted in Europe, ${ }^{14-17}$ but there remains a reluctance to its use in the USA. ${ }^{18}$

It is hard to pick up a prehospital or trauma journal in which there is not yet another review of what intravenous fluids should be used, and how much. This must, surely, be one of the most talked about areas of prehospital care, and yet true consensus evades us. Serious efforts are, however, being made to resolve this, and, encouragingly, the Faculty of Pre-hospital Care of the Royal College of Surgeons of Edinburgh has embarked upon, hopefully, the definitive study on the use of hypertonic saline in the prehospital environment.
Work from Los Angeles has cautioned us with regard to unnecessary intubation of patients with head injuries in the urban environment,' but, as mentioned above, this may not necessarily be the case in other scenarios. The vigorous use of hyperventilation in head injuries has been modified.

In addition to clinical advances, work has been done in other areas. Medical dispatch is being improved, protocols are being modified and improved software is assisting. Medical dispatch is evolving into a separate career option. More logical use of expensive resources such as helicopters is occurring, the exuberant reactions of some of the flight crews being tempered by clinical outcome recognition and financial realities, but more (non-emotional) audit is needed in this area. The utilisation and training of prehospital doctors is becoming more standardised, and the necessity of appropriately trained and experienced physicians as medical directors of prehospital and EMS activities recognised. The Diploma, and now the Fellowship in Immediate Medical Care of the Royal College of Surgeons of Edinburgh is playing a most important part in this in the United Kingdom.

The continuing involvement of the Faculty of Pre-hospital Care and the Faculty of Accident and Emergency Medicine in prehospital care is fundamental to this evolving branch of emergency care, and bodes well for the future. The development of appropriate indicators for the accurate assessment of the effectiveness of prehospital care should be a priority for both, so that true evidence based recommendations can be developed for prehospital care.

Emerg Med J 2003;20:1 14-115

\section{Author's affiliations}

C MacFarlane, Gauteng Provincial

Government, South Africa

Correspondence to: $\operatorname{Dr} C$ MacFarlane, White Gables, 29 Athlone Road, Parkview, Johannesburg, 2193, South Africa;

wmdmac@mweb.co.za

\section{REFERENCES}

1 Spaite DW, Valenzuela TD, Meislin HW, et al. Prospective validation of a new model for evaluating emergency medical services systems by in-field observation of specific time intervals in pre-hospital care. Ann Emerg Med 1993;22:638-45.

2 Spaite D, Benoit R, Brown D, et al. Uniform pre-hospital data elements and definitions: a report from the uniform prehospital emergency medical services data conference. Ann Emerg Med 1995;25:525-34

3 Callaham M. Quantifying the scanty science of prehospital emergency care. Ann Emerg Med 1997;30:785-90.

4 Blackwell TH, Kaufman JS. Response time effectiveness: comparison of response time and survival in an urban emergency medical services system. Acad Emerg Med 2002; 9:288-95.

5 Sampalis JS, Lavoie A, Salas M, et al. Determinants of on-scene time in injured patients treated by physicians at the site. Pre-hosp Disaster Med 1994;9:178-88.

6 Sampalis JS, Lavoie A, Williams JI, et al. Impact of on-site care, prehospital time, and level of in-hospital care on survival in severely injured patients. J Trauma 1993;34:252-61.

7 Liberman M, Mulder D, Sampalis J. Advanced or basic life support for trauma: meta-analysis and critical review of the literature. J Trauma 2000;49:584-99.

8 Demetriades D, Chan L, Cornwell E, et al. Paramedic vs private transportation of trauma patients. Effect on outcome. Arch Surg 1996:131:133-8.

9 Murray JA, Demetriades D, Berne TV. Prehospital intubation in patients with severe head injury. J Trauma 2000;49:1065-70.

10 Jacobs LM, Sinclair A, Beiser A, et al. Prehospital advanced life support: benefits in trauma. J Trauma 1984;24:8-13.

11 Potter D, Goldstein G, Fung SC, et al. A controlled trial of prehospital advanced life support in trauma. Ann Emerg Med 1988;17:582-8.

12 Shuster M, Shannon HS. Differential prehospital benefit from paramedic care. Ann Emerg Med 1994;23:1014-21.

13 Barkana Y, Stein M, Scope A, et al. Pre-hospital stabilization of the cervical spine for penetrating injuries of the neck - is it necessary? Injury 2000;31:305-9

14 Stern R, Arntz HR. Prehospital thrombolysis in acute myocardial infarction. Eur J Emerg Med 1998;5:471-9

15 Lamfers EJ, Hooghoudt TE, Uppelschoten A, et al. Effect of prehospital thrombolysis on aborting acute myocardial infarction. Am J Cardial 1999;84:928-30.

16 Arntz HR. Prehospital thrombolysis in acute myocardial infarction. Thromb Res 2001;103:591-6.

17 Pitt K. Prehospital selection of patients for thrombolysis by paramedics. Emerg Med J 2002; 19:260-3.

18 Bass RR. Current state of the art in the management of patients with acute myocardial infarction and ischemia within the Maryland Emergency Medical Service system. Md Med J 1997; (suppl):59-63. 
Emergency care

\section{Turbulent times}

\section{J Wardrope, P Driscoll}

\section{The pace of reform may exceed capacity}

W e thank David Lammy, ${ }^{1}$ George Alberti, $^{2}$ and Matthew Cooke ${ }^{3}$ for their thought provoking editorials. We also appreciate the contributions for the "For debate" section. Some may find the views of Leaman ${ }^{4}$ extreme but we sense that he articulates the thoughts of many A\&E clinicians concerning progress in reforming the emergency care system. "See and treat" is not a new idea. Professor Tony Redmond when he was in charge of North Staffordshire developed this model of a senior clinician at the front door. ${ }^{5}$ It makes a lot of sense to bring forward some of the decision making and starting investigations as soon as possible. $^{6}$

Leaman $^{4}$ and Windle ${ }^{7}$ both make the important point that this is yet another initiative that catches the imagination of managers and politicians. As a result it is being pressed into service across the country without a detailed assessment of the efficiency, cost efficiency, or sustainability. NHS Direct, Walk in Centres, face to face computer triage are examples of other centrally driven initiatives that were implemented without adequate evidence. They certainly have been "successful" in that lots of people use these facilities. Unfortunately this has been due to the creation of new demand for NHS resource, rather than helping with the existing workload in A\&E or primary care. $^{89}$ Instead this new demand has sucked up resource and staff that might have been more effectively employed in primary care or in A\&E. We will never know the answer to these questions, for trials with adequate design have not been carried out.

As Leaman ${ }^{4}$ quite correctly points out the main problem facing the NHS is lack of capacity to meet the demands of modern health and social care. The old NHS was based on the philosophy of the" greatest good for the greatest number". The aspiration of the new NHS is the best possible care for all, a laudable aim but hopelessly idealistic with current resources and staffing. ${ }^{10}$ Add to this the huge new demands of the medico-social needs of older patients and the cracks appear in the emergency care system.

Lammy ${ }^{1}$ assures us that new resources are being put into the NHS to try and provide better care. Alberti, ${ }^{2}$ Cooke, ${ }^{3}$ and Castille and Cooke $^{11}$ point out that new ways of working may help this problem. Things are improving, mainly for patients with minor problems but the intractable problems of lack of capacity to handle admission workload remain.

Long waits in A\&E are the symptom of the malaise that is taking hold of our current systems. Dealing with symptoms rather than the root cause of the disease is like giving an aspirin for headache to a patient with a subarachnoid haemorrhage. This might improve the most pressing problem but leaves us with the potential disaster of system melt down as our departments struggle under the weight of acute medical admissions. Work by Cooke (Cooke MW, et al, annual scientific meeting Faculty of Accident and Emergency Medicine 2002) and Miro $^{12}$ show that the main determinants of A\&E overcrowding are hospital bed occupancy and availability of medical beds.

If "See and treat" brings new additional experienced staff, more resources and more space to our departments, then it should be welcomed. We all want more staff. We all want to reduce waiting times. We all want to provide a good service. However, we cannot divert existing staff to deal with minor injuries without convincing evidence that it does not compromise care of the more serious cases or simply transfer the bottle neck of patient flow to another part of the system.
Operational research in A\&E is often difficult and hard to fit into the "randomised trial" pattern but well conducted studies are possible but they need to be thought of as part of the implantation of a new initiative, not as an afterthought. In doing such studies we need to aim to improve all the aspects of quality of patient care-not just speed through the department. Consequently the in house clinicians, trust managers, and the A\&E specialists all must be willing to change.

This edition of the EMJ brings together a huge amount of material on the organisation and delivery of emergency services. We hope it will provoke discussion and debate. The care we deliver to our patients is probably as dependent on sound managerial structures and processes as on individual clinical excellence. We await your responses to emjonline.

Emerg Med J 2003;20:1 16

\section{Authors' affiliations}

J Wardrope, P Driscoll, Joint Editors

Correspondence to: www.emjonline.com

\section{REFERENCES}

1 Lammy D. Reforming emergency care; for patients. Emerg Med J 2003;20:112.

2 Alberti KGMM. Skillmix: an advance or an excuse. Emerg Med J 2003;20:1 12-13.

3 Cooke MW. Reforming the UK emergency care system. Emerg Med J 2003;20:1 13-14.

4 Leaman AM. See and Treat: one size does not fit all. Emerg Med J 2003;20:118.

5 Redmond AD, Buxton N. Consultant triage of minor cases in an accident and emergency department. Arch Emerg Med 1993;10:328-30

6 Lindlay Jones $M$, Findlayson B. Triage nurse requested x-rays. Are they worthwhile? J Accid Emerg Med 2000; 17:103-7.

7 Windle J, Mackway-Jones K. See and Treat: don't throw triage out with the bathwater. Emerg Med J 2003;20: 1 19-20.

8 Munro J, Nicholl J, O'Cathain A, et al. Impact of NHS Direct on demand for immediate care: observational study. BM 2000;321:150-3.

9 Salisbury C, Chalder M, Manku-Scott T, et al. The National Evaluation of NHS Walk-in Centres. Final report. Bristol: University of Bristol, 2002

10 Wardrope J. Unlimited consumer demand would destroy the NHS. BM 2001;322:1369.

11 Castille K, Cooke MC. See and Treat: one size does not fit all. Emerg Med J 2003;20:120-2.

12 Miró Ó, Sánchez, M, Espinosa G, et al. Analysis of patient flow in the emergency department and the effect of an extensive reorganisation. Emerg Med J 2003;20:143-8. 


\section{The NICE head injury guidelines}

D W Yates

\section{The need for guidelines for head injury}

$\mathrm{E}$ mergency physicians are already surrounded by guidelines. Surely, you might ask, we don't need more on head injury to add to those of the US Brain Trauma Foundation, the European Brain Injury Consortium, the SIGN guidelines from Scotland, and recent recommendations from UK neurosurgeons, radiologists, paediatricians, and anaesthetists? Well, yes, I think we do. The guidelines to be published by the National Institute for Clinical Excellence in Spring 2003 will break new ground in a number of ways that will be of particular interest to our specialty. ${ }^{1}$

The development of the guidelines follows the pattern of best evidence synthesis, resolution of uncertainty by expert consensus, and consultation with a wide spectrum of professional and stakeholder groups that has been used so effectively in the production of National Service Frameworks. The work has been carried out at the recently created National Collaborating Centre for Acute Care, part of NICE, which is located at the Royal College of Surgeons of England.

The parameters of the task were laid down by NICE. Their general philosophy is refreshingly patient centred and will appeal to emergency physicians-the guidelines are intended to help improve both the quality and consistency of clinical care by making available to health professionals and patients well-founded advice based on the best available evidence. ... not written from the perspective of any individual health care profession. These objectives were reflected in the composition of the Guideline Development Group, which included not only the expected professionals (three from emergency medicine) but also experienced and articulate patient representatives. The real work was undertaken by a project team, which included systematic reviewers, a statistical adviser, an A\&E trainee, an information scientist, and a health economist, lead by a graduate project manager. This team spent over 12 months reviewing the extensive literature, determining the level of evidence in each topic area (based on previously accepted definitions), and producing grades of recommendation according to the quality of the evidence. Where the evidence was inadequate the problem was brought to the Guideline Development Group so that expert opinion (and hopefully consensus) could be considered. However, the supremacy of evidence was always acknowledged-albeit with frequent debate about the adequacy of the methodology behind that evidence. Here the professional experience of the project team was critical to success.

While this methodology is widely acclaimed as the best way to approach such a task, a number of problems were encountered. The most difficult were the identification of the boundaries of the guidelines and the paucity of class 1 evidence. Resources and time constraints dictated that the scope be limited to initial assessment, where it was considered that there was the greatest potential health gain. Management was studied up to the point of specialist inpatient team care. It was acknowledged that the longer term care of the many patients with so called mild head injury was often inadequate and that the burden of associated disability demanded attention. However, it was considered to be outside the remit of the group, which limited its comments to a call for research investment in this area.

A period of consultation with international experts, patient groups, and professional bodies was completed in December 2002 and the draft guidelines modified in response to the many constructive comments received. The revised draft was then posted on the NICE web site to encourage dialogue with a wider audience. After any further modification, the documents will then be published by NICE in three forms-a comprehensive report with appendices and extensive bibliography, a short form (running to over 20 pages), and a patient orientated version. However, this will not be the end of the process. There are many areas, particularly in prehospital care and rehabilitation, where the document will, rather lamely, admit that current practice should continue until adequate evidence has been accumulated to more appropriately direct care on an evidence base. It is to be hoped that this unacceptable state of knowledge will act as a prompt to researchers and to funding bodies so that head injury, with its associated youthful mortality and morbidity, can receive the attention it deserves.

Until then, what can we expect to change as a result of the publication of the NICE guidelines? The most challenging will be the strong recommendation that "CT diagnosis" replace "radiological triage" in the investigation of most head injured patients meeting certain prescribed criteria. Concerns about service provision have clouded this issue for too long. Happily, the Guideline Development Group were specifically advised that such issues were outside their terms of reference-and so they should be.

Nevertheless, there will be concern about the service implications of this evidence based recommendation. It is possible that a phased introduction of the guidelines may be deemed sensible to test this and other potential adverse consequences. Certainly it will be necessary to audit guideline use and, hopefully, their effectiveness. It should be possible to adapt North American data to guide us on the level of CT and radiography use we can expect. The use of CT to image the cervical spine in the head injured patient is a more complex issue, but the evidence points to the continued use of radiography in the great majority of cases, with CT reserved for a few specific situations. A literature review indicates that there is stronger evidence of the potential harm from CT in the neck than from CT to the child's skull.

The full version of the NICE guidelines extends to 90 pages. It provides a snap shot of current evidence and the best synthesis of international expert opinion available. It seeks to meet the aspirations of patients and professionals and has been written from a multidisciplinary perspective. Its objective is to improve the quality and consistency of clinical care. There is an implicit assumption that its impact will be assessed through audit and that the research community will address the extensive evidence free zones in head injury management. One way to promote these developments might be to extend the remit of the National Collaborating Centre for Acute Care to include collaboration with a recently rejuvenated committee in the same building, the College Trauma Committee.

Emerg Med J 2003;20:117

\section{Author's affiliations}

D W Yates, University of Manchester, Hope Hospital, Salford M6 8HD, UK

Correspondence to: Dr D W Yates: david.w.yates@man.ac.uk

\section{REFERENCE}

1 National Institute for Clinical Excellance.

NICE web site. (http://www.nice.org.uk/) 